\title{
Long Period Fiber Grating Produced by Arc Discharges
}

\author{
Julián M. Estudillo-Ayala1, Ruth I. Mata-Chávez', \\ Juan C. Hernández-García ${ }^{2}$ and Roberto Rojas-Laguna ${ }^{1}$ \\ 1 Universidad de Guanajuato \\ ${ }^{2}$ Centro de Investigaciones en Óptica A.C. \\ México
}

\section{Introduction}

Fiber Gratings are found among the most popular devices widely used in both, optical communications and optical fiber sensing. Within optical communication networks, optical fiber-based devices perform critical operations such as coupling/splitting, wavelengthselective filtering, and optical switching (Han, Y. G. et al., 2004; An H. et al., 2004; Eggleton B. J. et al., 1997). In the field of optical sensing, optical fiber sensors, with unique advantages such as immunity to electromagnetic interference, high sensitivity, resistance to corrosion, and high temperature survivability, are widely used to measure various physical variables such as stress, temperature, pressure, refractive index, etc. and chemical parameters (Udd, E. 1991).

There are two types of fiber gratings that have been developed so far including the Fiber Bragg Grating (FBG) and the Long Period Fiber Grating (LPFG). One important advantage respect to Bragg gratings is that their fabrication process is simpler; their cost is lower. Furthermore, they present low retro-reflection and high sensitivity in sensing applications (Kersey, A. D. et al., 1997).

LPFGs have been traditionally fabricated by exposing photosensitive optical fiber to ultraviolet (UV) light transversely. Either through an amplitude mask or point-by-point to create a periodic refractive index change inside an optical fiber. Unfortunately, the UVinduced refractive index changes inside an optical fiber can only survive at a relatively low temperature. As a result, the UV exposure fabricated-LPFGs are not suitable for high temperature applications. Among the different techniques available for the fabrication of LPFGs, the electric arc technique is one of the few enabling their fabrication, virtually in any type of glass fibers. This technique is simple, inexpensive and harmless when compared to the ones based on laser radiation. Furthermore, arc-induced gratings are suitable for high temperature applications since their formation mechanisms rely on thermal effects. Thus, the temperature reached by the fiber during an electric arc discharge, is a key parameter to understand the properties of gratings (Rego, G. 2010). An LPFG can be considered a special case of a fiber Bragg grating, in which the period of the index modulation satisfies a phase matching condition between the fundamental core mode and the forward-propagating cladding-mode of an optical fiber. Therefore, an LPFG consists of a periodic spatial variation 
(along the fiber longitudinal axis) in the refractive index of an optical fiber. The periodic refractive index modulation couples light from a forward-propagating core-guided mode, to forward-propagating cladding-guide modes, near certain resonance wavelengths (Vengsarkar, A. M. et al., 1996). The light coupled into the cladding modes, eventually attenuates due to the high loss of the cladding modes. As a result, the transmission spectrum of a LPFG has a series of discrete attenuation bands near the resonance wavelengths. In this chapter we will describe two of the in-fiber LPFGs fabrication methods: optical fiber fattening and optical fiber micro-taper, both methods by means of electric arc (we used a splicer fusion of optical fiber). We will present several configurations of PFGs sensors as well as temperature and curvature sensors. Finally, at the end of this chapter, we will show numerical calculations of the modal behavior of the LPFGs, besides conclusions and references.

\section{Fiber grating}

One of the most important discoveries, in the field of optical fibers, has undoubtedly been made by Hill et al. in 1978 (Hill, K.O. et al., 1993; Hill, K.O. et al., 1997). Working in their laboratories [The Communications Research Center (CRC) in Ottawa, Canada.], they carried out an experiment to study nonlinear effects in an optical fiber especially designed by Koichi Abe of Bell Northern Research. This special optical fiber had a high germanium concentration, a numerical aperture of 0.22 at $514.5 \mathrm{~nm}$, and the fiber core diameter was of $2.5 \mathrm{~mm}$. They launched intense light of Argon-ion $(514.5 \mathrm{~nm})$ laser into the core of a Germania-doped fiber, and several minutes after, they observed the power beam decreasing. Subsequent to this observation, they monitored the light back reflected from the fiber, finding that the power significantly increased with time. The increase in the reflected light was produced by the writing in the core of the fiber by an interference periodic pattern (hologram), corresponding to a periodic modulation of the refraction index in the optical fiber core. This nonlinear effect in optical fiber was called fiber photosensitivity, and the holograms in the core of the fiber are called "Hill gratings" (Hill \& Meltz, 1997; Othonos, 1997; Hill, 2000).

After the discovery of the photosensitivity in optical fibers, the effect was forgotten by several years, due to restrictions in the writing of the grating. However, a new interest emerged after the proposal of Meltz et al. 1989, where they described the grating fabrication, producing the overlapping of two coherent beams of ultraviolent light (Meltz, G., et al., 1989). Beams interfered between them, creating a periodic interference pattern with both bright and dark bands, which generated a permanent grating with the same refraction index of the fiber. This technique was called the transverse holographic technique. This is possible because of the cladding of the fiber is transparent to the ultraviolet radiation, while the core strongly absorbs this kind of light due to the germanium concentration. Hill et al. 1993 proposed a simple way to fabricate gratings. They did not use an interferometer; instead, they used a beam of ultraviolet light placing a glass phase mask of pure silica, very close to the fiber (Othonos, A. et al. 1997). The grating was formed by exposing the fiber to ultraviolet light through the phase mask. Therefore, it is one of the most efficient methods for inscribing gratings in photosensitive fiber.

This novel method represented the key for simpler and more accelerated fabrication of gratings in special fibers. Nowadays, these gratings are employed in the fabrication of 
devices for optical communications (fiber lasers, filters, optical switching, and multiplexers) and optical sensing applications.

\subsection{Basic concepts}

The optical fiber gratings are a special type of filter wavelength selective operating in reflection or transmission with the fundamental principles of reflection, refraction and diffraction of light in periodic structures dimensionless. These basic components are formed when the refractive core index of a fiber section is periodically modulated. According to their operation, there are two types of optical fiber grating: Bragg Gratings (BG) and LongPeriod Gratings (LPG). The Bragg gratings are called this way because their operation is based on the Bragg reflection law (Kashyap R., 1999). The Bragg gratings were inscribed by the first time in fiber optics, with the discovery of photosensitivity as it was mentioned previously. The main characteristic of this type of BG is the possibility to reject a narrow band of wavelengths (which meet the Bragg condition). Fig. 1 shows a diagram which illustrates the operation of a Bragg grating. When the signal intensity $\mathrm{P}_{\mathrm{I}}$ (broadband light source) is propagated along the $B G$ in the optical fiber, a signal $P_{B}$ centered at the Bragg wavelength and a narrow band is reflected $(<1 \mathrm{~nm})$. On the other hand, the transmitted signal $\mathrm{P}_{\mathrm{T}}$, shows a band rejection to Bragg wavelength.

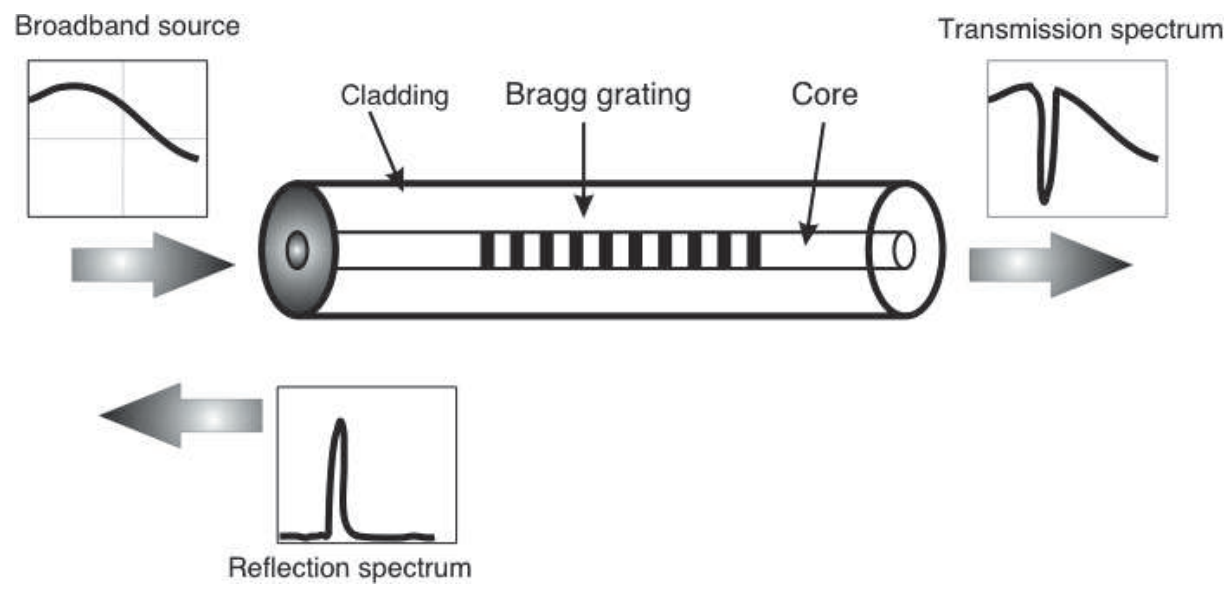

Fig. 1. (a) Schematic diagram of a sampled FBG, Signal spectra of input $\left(\mathrm{P}_{\mathrm{I}}\right)$, $\operatorname{reflected}\left(\mathrm{P}_{\mathrm{B}}\right)$ and transmitted in a Bragg grating $\left(\mathrm{P}_{\mathrm{T}}\right)$.

\section{Long Period Fiber Grating}

The long period fiber gratings (LPFG) has a period typically in the range from $100 \mu \mathrm{m}$ to $1000 \mu \mathrm{m}(1 \mathrm{~mm})$, as we show in Fig. 2. An LPFG introduces a coupling between the fundamental guided mode and propagating cladding mode (Riant, I. 2002). In Fig. 3, we show the transmission spectrum of a LPFGs photoimprinted in a standard fiber. The wavelengths of the peaks shown in Fig. 3 are defined as (Erdogan, T. 1997).

$$
\lambda^{m}=\left(n_{e f f}^{01}-n_{e f f}^{m}\right) \Lambda
$$


Where $n_{\text {eff }}^{01}$ and $n_{\text {eff }}^{m}$ represent the effective indices of the fundamental guided mode, the cladding mode of order $m$ coupled to the guide mode by the grating respectively, then $\Lambda$ is the period of the LPFG.

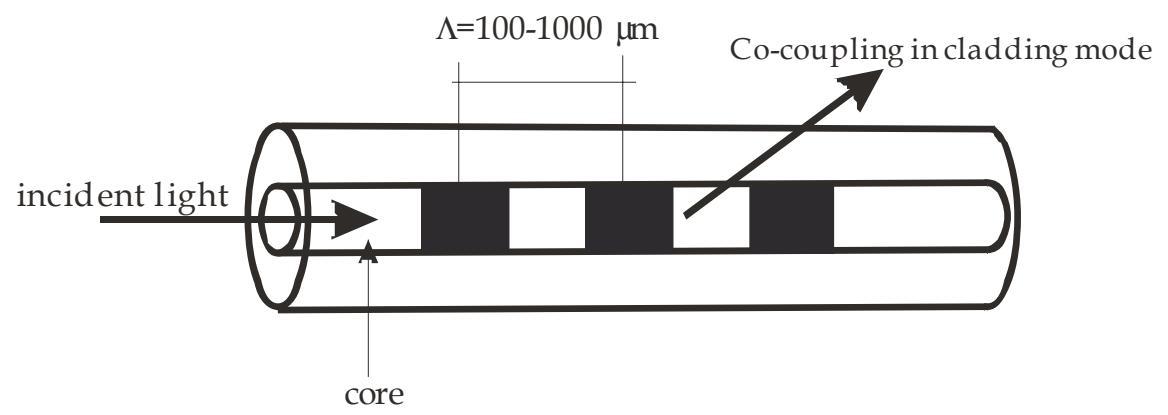

Fig. 2. Schematic diagram of a long-period fiber grating. The period of the grating is $\Lambda$.

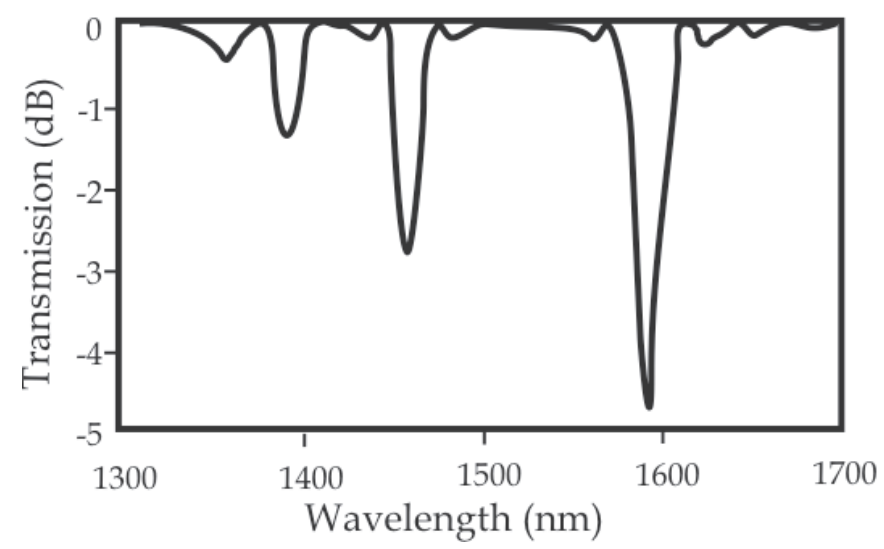

Fig. 3. Depicts transmission spectrum characteristic of a Long Period Grating

Coupling between two propagating modes occurs for periodicity of several hundreds of microns, which are three orders of magnitude larger than for short period grating.

The minimum transmission of the attenuation bands is governed by (Kashyap, R. 1999).

$$
T_{i}=1-\sin ^{2}\left(\kappa_{i} L\right)
$$

Where $L$ is the lenght of the LPFG and $\kappa_{i}$ is the coupling coefficient for the $i$ th cladding mode, which is determined by the integral overlap of the core and cladding mode, also by the amplitude of the periodic modulation of the mode propagation constants.

Since the cladding generally has a large radius, it supports a large number of cladding modes. Theoretical analysis has shown that efficient coupling is possible only between core and cladding modes which have a large integral overlap, in other words, modes which have similar electric field profiles (Erdogan, T. 1997). This coupling is observed between the core and circularly symmetric cladding modes of odd order. The effect occurs because the electric 
field profile of the even-order modes is such that the field amplitude is low within the core (Erdogan, T. 1997). The refractive index of the propagating core mode of the fiber is generally determined using the weakly guided field approximation (Glogle, D. 1971). A simple three-layer slab waveguide model, to determine the cladding mode indices, has been presented, allowing an approximate determination of the coupling wavelengths (Vengsarkar A.M. et al., 1996).

\subsection{Fabrication techniques of long-period gratings in optical fiber}

The long period grating fabrication in an optical fiber consists of a refractive index periodic modulation of the optical fiber core. This modulation may be permanent or temporary. The permanent modulation can be obtained by irradiation or heating. The temporal modulation index can be achieved by mechanical pressure or acoustic vibrations through the photoelastic effect. The modulation of the core refractive index has been achieved by being used with different types of optical fibers, for example, standard single mode, photo-sensible, photonic crystal fiber, specialty optical fibers, among others. Techniques like UV irradiation (Ultraviolet) (Vengsarkar A.M. et. al., 1996; Bhatia, V. et. al. 1996; Erdogan, T. 1997), laser $\mathrm{CO}_{2}$ exposure (Davis, D. D., et. al., 1998; Davis, D. D., et. al., 1999), electric arc discharge, mechanical microbends, etched corrugations, ion beam implantation, femtosecond laser exposure, just to mention a few, have been developed for more than a decade. Different devices based on LPFG have been fabricated for applications in optical communications as well as in sensors.

\subsection{Techniques of fabrication by arc discharges}

The Long Period Fiber Gratings (LPFG) fabricated with electric arc, have been widely used as filters in telecommunication networks, as well as the sensing element for various physical and chemical parameters. These applications are possible due to their relevant characteristics, such as: very deep attenuation band and narrow bandwidth. In addition, the period is easily adjustable, allowing the wavelength to tune over a wide range (from 1300 to $1700 \mathrm{~nm}$ ). However, disadvantages of the LPFGs are their low repeatability and the wavelength of the attenuation bands has higher level of losses compared to other technologies (UV-inscribed techniques). Disadvantages are largely due to two issues: first, to the random nature of the arc, and second, the physical deformation that occurs in the optical fiber. In this chapter, we describe the development of LPFG when electric arc discharge is applied. The electric arc can produce geometric deformation, which might increase the coupling of modes, but in many cases it induces losses. There are three main types of modulation: modulation only of the refractive index, the modulation by microtaper, and microbends.

\subsection{Modulation only of the refractive index}

The best way to inscribe an LPFG is through merely changing the refractive index of the core, without affecting the geometry of the fiber. In this case, the attenuation bands are well defined and out of these ones, there are no losses. Fig. 4 shows the transmission spectrum of a long-period grating inscribed by ultraviolet radiation (LPFG-UV), this kind of gratings meet these conditions. In the LPFG by electric arc (LPFG-EA) this type of modulation can be obtained, but unlike LPFG-UV, in this type of gratings the refractive index of the cladding is 


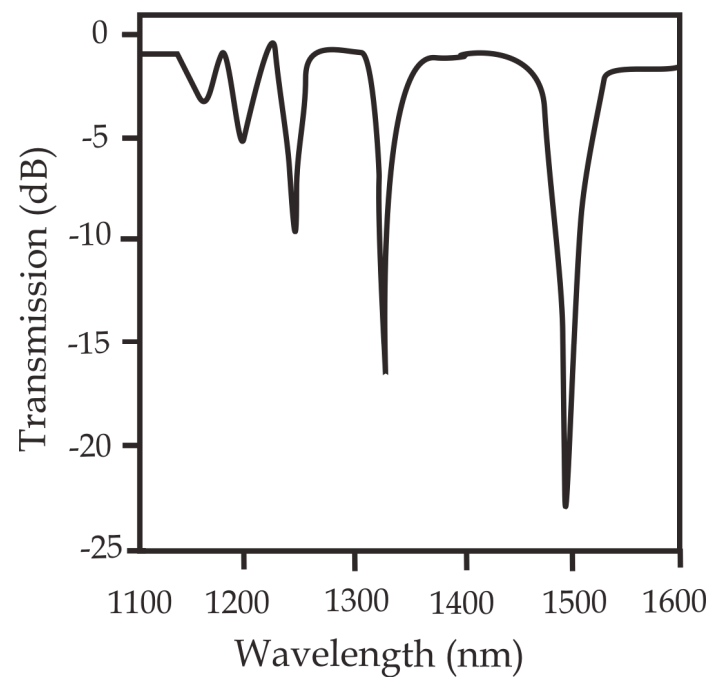

Fig. 4. Transmission spectra of a LPFG modulated only of the refractive index (LPFG-UV) (Stephen, W.J., et. al., 2003).

always modulated and geometric changes occur. The modulation of both refractive indices increases insertion losses, because the single mode condition is different, and moreover, the coupling constant is larger. The latter means that in general, the LPFG-EAs are of shorter length than LPFG-UV and easily, achieve greater levels of attenuation. While LPFG-UV typically require a grating length of 1 inch to achieve a rejection level of $18 \mathrm{~dB}$, the LPFG-EA require approximately $2 \mathrm{~cm}$.

The pure Refractive Index Modulation (RIM), in the electric arc technique, is quite difficult to achieve, as usually, it uses axial stress for greater change in refractive index, producing micro-bending or micro-tapers.

\subsection{Periodic modulation by micro-taper}

During an electrical arc discharge, an optical fiber can reach temperatures above $1350{ }^{\circ} \mathrm{C}$ (Rego G., 2006). This temperature is sufficient to soften the silica $\left(\mathrm{SiO}_{2}\right)$ and make it pliable. This is the principle used for taper manufacture of optical fiber and fiber couplers couplers. This procedure to make a fiber taper is used to inscribe a LPFG. Due to the low weight (less than $200 \mathrm{~g}$ ) and short electric discharge (hundreds of milliseconds), the tapered length is in the order of micrometers. So, actually, a micro-taper is achieved by every arc discharge, see fig. 5 .

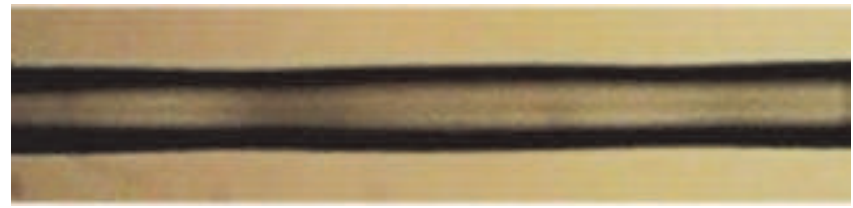

Fig. 5. Micrography of the induced tapers (Myoungwon K., et al., 2002) 
In the micro-tapers of fiber, the best option is to reduce the fiber in symetrically shape, as shown in Fig. 6(a). Unfortunately due to factors such as: misalignment, accidental twist or tension, it is not exactly axial, and then an LPFG can be obtained as shown in Fig. 6(b). This mismatch of fiber alignment generates losses as the electromagnetic fields cannot be guided properly. In addition, birefringence is induced because the core is deformed asymmetrically. These features are present in micro-tapers. In the context of the LPFG-EAs, producing micro-tapers with a symmetrical shape is possible because the gratings allow good contrast with shorter length. Also, if handled properly, the procedure of micro-taper can be achieved with minimal levels of losses of RPLA similar to those obtained in other inscription techniques. The asymmetry can be reduced with a good alignment, while for narrow fiber, it is necessary to properly choose the parameters of the technique, in order to achieve an optimal micro-taper.

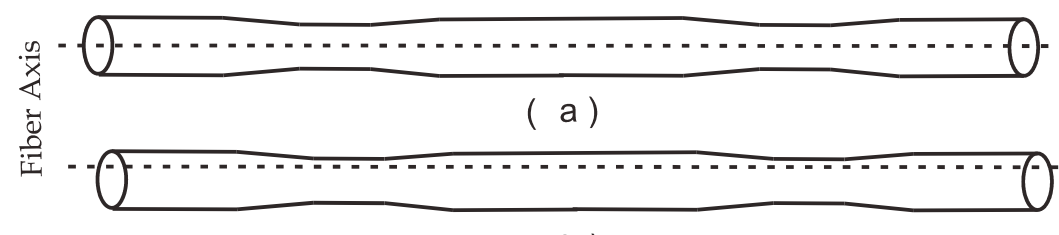

( b )

Fig. 6. Two types Microtapers of LPFG: (a) symmetric, (b) asymmetrical

\subsection{Periodic modulation by microbends}

The Modulation by microbends was presented by In Kag Hwang et al. (1999). In Fig. 7, an unjacketed optical fiber is held straight by two fiber holders, separated by $5.5 \mathrm{~cm}$, which limits the maximum grating length. One of the fiber holders is then displaced (by $100 \mu \mathrm{m}$ ) in the orthogonal direction of the axis fiber so that a lateral stress is induced on the fiber between the two fiber holders. When a local section of the fiber is heated by application of an electric arc, the fiber is slightly deformed owing to the lateral stress, creating a microbend. The amplitude of the microbend is controlled by the duration of the arc and is typically less than $1 \mu \mathrm{m}$. Most of the originally applied lateral stress remains in the fiber.
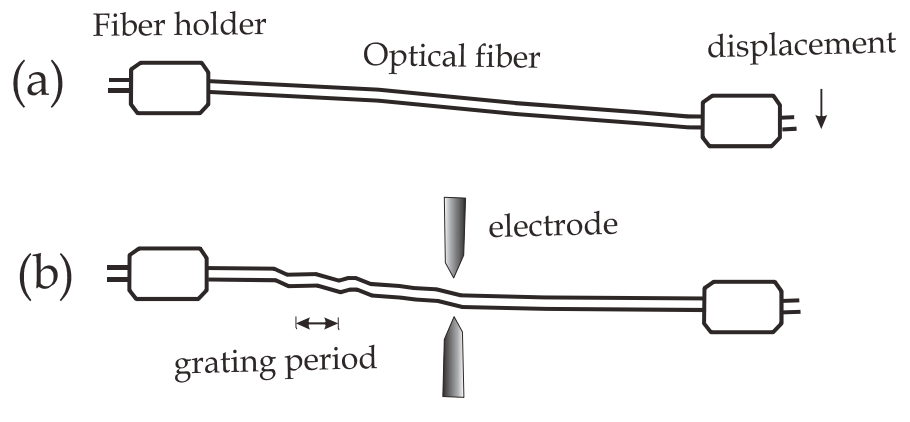

(c)

Fig. 7. Fabrication of a LPFG based on periodic microbends by use of an electric arc.(Hwang, I. K., et al. 1999). 
Translating the electrodes by the grating period and applying electric arcs, one can create successive microbends without additional displacement of the fiber holder. In this way, a permanent microbend structure is inscribed in an optical fiber, as shown in Fig. 7(c).

Another way to induce microbends is applying many arc discharges at the same point and contrary to the microtapers, when applying the discharge; the glass is compressed axially over the fiber. This will result in a fattening of the area under the electric arc discharge. Fig. 8 shows a long period fiber grating, based in fiber fattening. These LPFGs have very specific characteristics: the number of arc discharges are little, about 8 fattening points per grating and the attenuation bands reach a depth of almost $20 \mathrm{~dB}$. At the same time, the length of the LPFG is very short (about $0.5 \mathrm{~cm}$ ), but the level of losses that can be produce are at 1 to $2 \mathrm{~dB}$ (Mata-Chávez R.I., et al., 2008a).

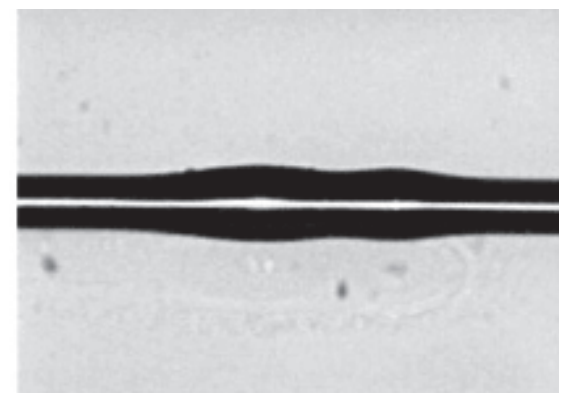

Fig. 8. Photograph of the fattened sections of the optical fiber. (Mata-Chávez R.I., et al., 2008).

\subsection{Fabrication of LPFG by the micro-taper method}

In these two sections we describe two fabrication methods of LPFGs by electric arc discharges: micro-tapers in which we show the experimental setup as well as data of the parameters used, and the method of fattening.

The gratings were fabricated in commercially avaible standard telecommunication optical fiber (SMF-28) using the point-by-point technique as shown in fig. 9. A bare single mode fiber without its protective coating was placed between the electrodes of a fusion splicer machine (Fitel S-175), while its ends were fixed on two Bare Fiber Adapters. A section of the fiber was fixed on a computer-controlled translation stage (Model NLS4, NEWMARK SYSTEMS INC.) wich a resolution of $1 \mu \mathrm{m}$.

The fusion splicer is operated in manual mode, and parameters such as arc current, prefusion time, and pushing distance are varied in order to control the grating period. Best results were observed when in the splicer machine the arc current was set up to $11 \mathrm{~mA}$, the pre-fusion time was $150 \mathrm{~ms}$, the arc duration time was of $250 \mathrm{~ms}$ and the Z-push was set to $1 \mu \mathrm{s}$, which rise the temperature of the fiber section positioned in between the electrodes to its softening point. The fiber was then moved by the translation stage along a distance equal to the grating period and another arc discharge along with tapering was applied. Care was taken to provide sufficient time between arcs to allow the fiber to get cooled. The periodical tapering continued and the optical transmission of the fiber was monitored during the LPFG 


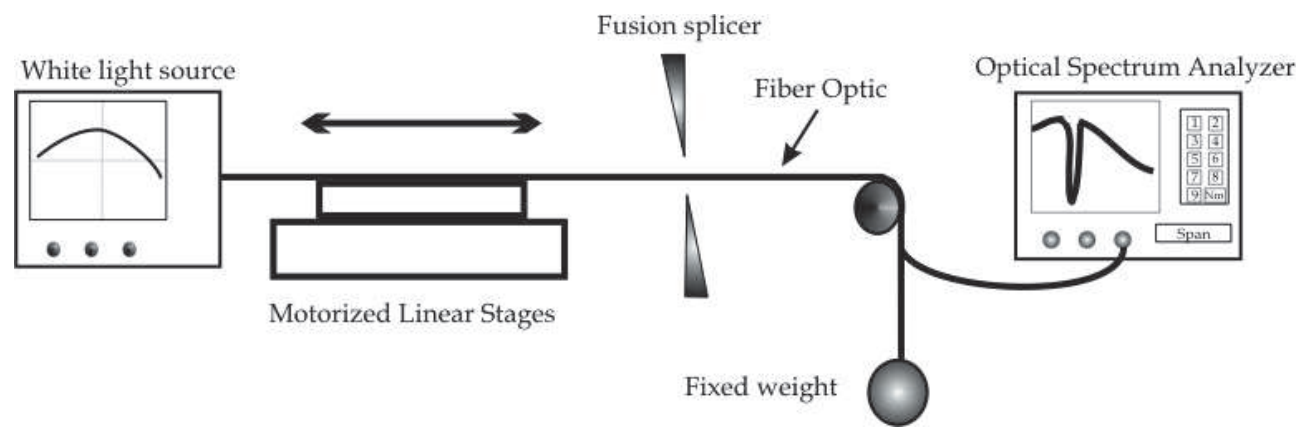

Fig. 9. Experimental setup used for fabrication LPFG by the micro-taper method.

fabrication process in order to obtain the desired spectral attenuation notches. The optical reading setup employed in the experiments were a white light source coupled to one end of the fiber, while the other end was connected to an optical spectrum analyzer, OSA (Yokogawa AQ6370B, Measurement wavelength range 600-1700nm ), set to a resolution of $0.1 \mathrm{~nm}$. The transmission spectrum was acquired and processed by a computer to determine the LPFG central wavelength of attenuation and transmittance. The size of the arc limited the minimum grating period $\Lambda$, and we got a peak attenuation of $22 \mathrm{~dB}$ at $1531 \mathrm{~nm}$ after 22 engravings with a grating period of $629 \mu \mathrm{m}$. The spectral evolution of the LPFG is shown in Fig. 10. illustrating the transmission spectra with various grating period numbers of $10,15,17,20$ and 21 .

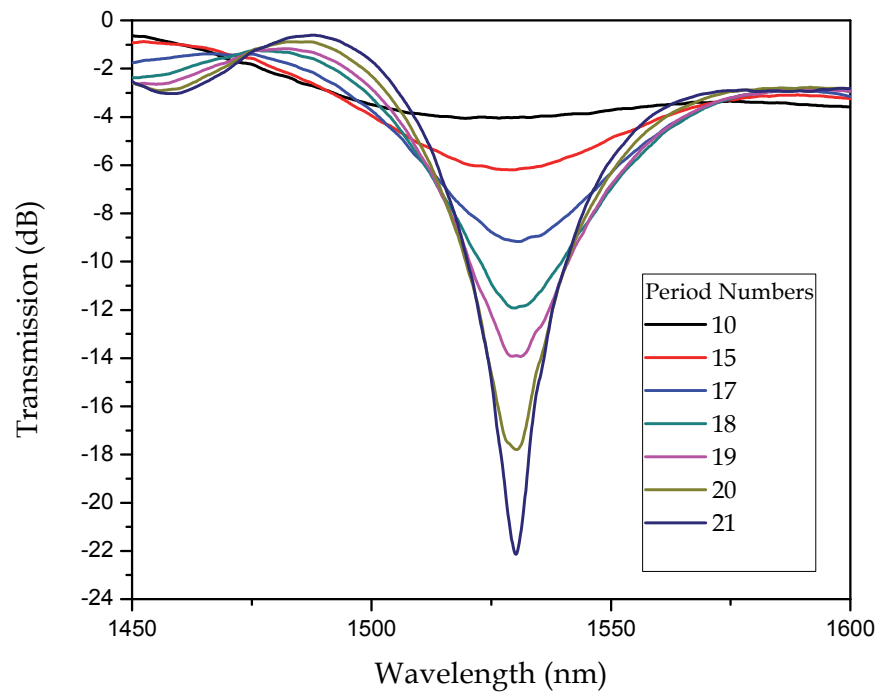

Fig. 10. Evolution of the LPFG spectrum

In fig. 11, it is shown spectra of LPFGs is depicted with different periods, we observed that for shorter periods, the attenuation peak shifts to the left, the LPFGs periods are $\Lambda=540 \mathrm{~nm}$, $560 \mathrm{~nm}, 580 \mathrm{~nm}$ and $600 \mathrm{~nm}$. 


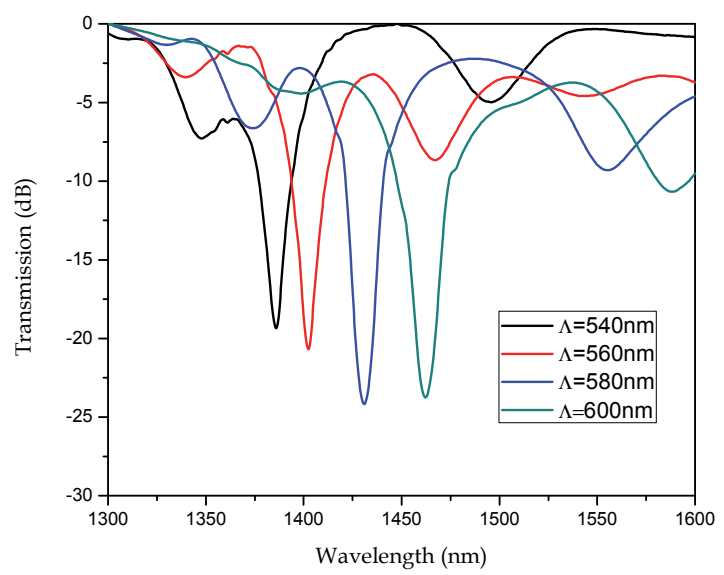

Fig. 11. Normalized transmission spectrum of some LPFGs with different periods.

\subsection{Fabrication of LPFG by the fattening method}

The fattening method used to fabricate long period fiber gratings consists in gradually enlarging the optical fiber diameter. This is achieved through applying several electrical discharges over an axial region and observing the transmission changes with an optical spectral analyzer. After applying the required discharges by the procedure in one point, the fiber is displaced by the motors of the fusion machine for a distance equal to the grating period (>150 microns) where the process is then repeated to enlarge again the fiber diameter (Mata-Chávez R.I., et. al., 2008a).

This procedure is repeated from two to six times (depending on the grating period) until filtering functions are observed. Fig. 12 depict the transmission loss band achieved by the method in a dispersion shifted fiber.

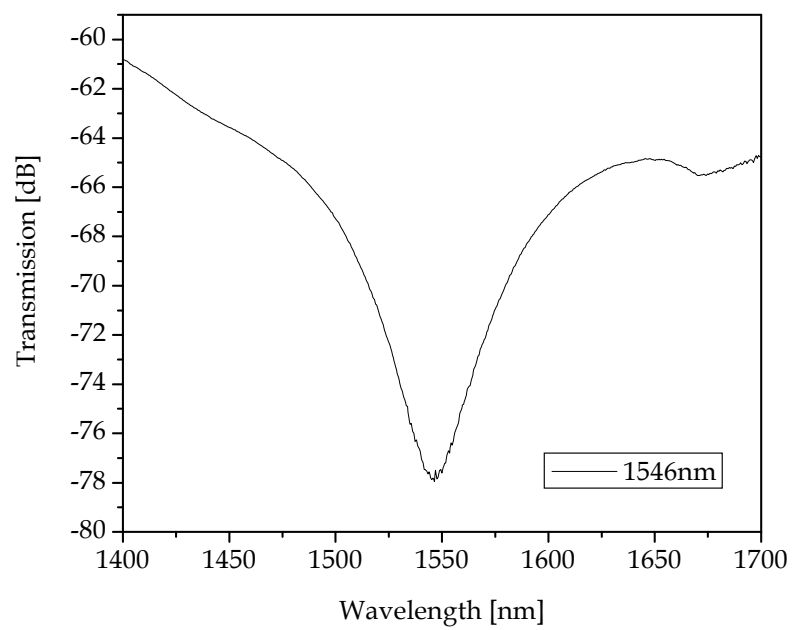

Fig. 12. Loss band of a fattened long period grating near $1550 \mathrm{~nm}$. 
The fusion splicer machine has resulted very useful for the fattening method. The standard fusion splice method is used to heat and soften the fiber (known as push delay) followed by a hot push to join the fiber tips (Yablon A. D. 2005). As the procedure is repeated the fiber gets a geometric deformation on its structure for which an energy coupling occurs of the fundamental mode of the fiber core to the radiation or leaky modes in the cladding. Fig. 13 depicts the time delay of the electric discharges applied to enlarge the fiber diameter in a point. Using this approach, wavelength band rejection filters have been obtained, this can be used as optical communication and sensing devices.

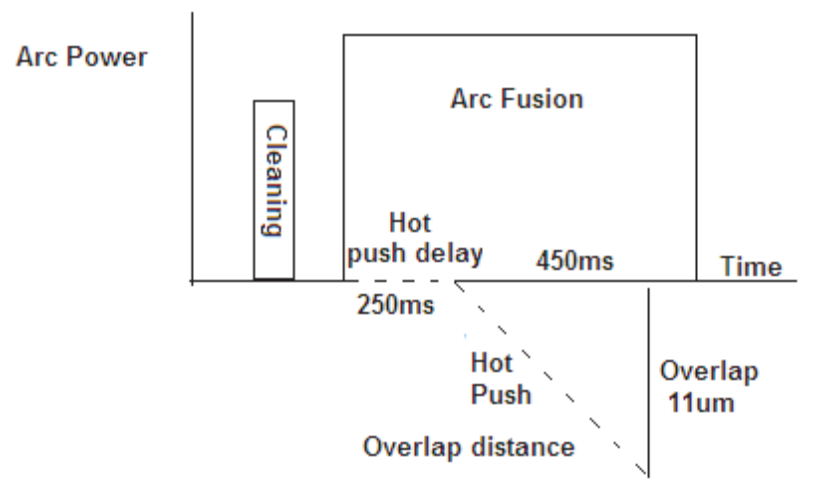

Fig. 13. Time delay of the standard discharged method.

The complete process is done in manual mode after choosing the correspondent optical type program and modifying several variables as arc power, arc duration, pre-fusion time and z-push distance. In fig. 13 can be observed an initial cleaning stage of low power to remove plastic and dust debris. Then, the fusion process continues with an electric arc discharge where the hot push delay heats the fiber to the softening point during $250 \mathrm{~ms}$. The hot push stage joins both tips by means of the motors of the machine for a distance of 11 microns. This process is repeated several times until a desired expansion of the diameter is achieved. The following values were initially used to fabricate LPFG in dispersion shifted fiber: Arc power $=85 \mathrm{~mW}$, Arc duration $=450 \mathrm{~ms}$, hot push delay $=$ $250 \mathrm{~ms}$ and $\mathrm{z}$ push $=11 \mu \mathrm{m}$.

\section{Devices produced by Long Period Fiber Grating}

Several LPFG fabrication methods are used with different types of optical fibers like standard single mode, photo-sensible, photonic crystal fiber, specialty optical fibers, etc. Techniques like UV irradiation (Ultraviolet) (Vengsarkar A.M., et. al., 1996a; (Vengsarkar A.M., et al., 1996b; Erdogan, T., 1997), laser $\mathrm{CO}_{2}$ exposure (Davis D. D., et. al., 1998; Davis D. D., et. al., 1999; Kakarantzas G., et. al., 2001), electric arc discharge (Humbert G., et al. , 2003; Dobb H., et. al., 2004; Rego G. M., et al., 2006b, mechanical microbends (Su L., et al., 2005), etched corrugations (Lin C. Y., et. al., 2001), ion beam implantation (von Bibra M. L., et. al., 2001), femtosecond laser exposure (Grobnic D., et al., 2006; Mihailov S. J., et al., 2006), etc. have been developed for more than a decade. Different devices based on LPFG have been fabricated for applications in optical communications and as sensors. 
Sensing applications with LPFG include temperature, strain, bend, torsion, pressure and biochemical sensors because of the sensitivities of resonance wavelength and attenuation amplitude of these measured parameters. Variations of these measurands respond to the fabrication method and optical fiber type that influence on the grating length and optical characteristics of every sensor.

Optical telecommunications find useful applications for LPFG as band rejection filters (Mata-Chávez R.I., et. al., 2008a; Hernández-García J.C., et. al., 2010), gain equalizers for erbium doped fibers (Vengsarkar A.M. et al., 1996a; Vengsarkar A. M., et al., 1996b) , fiber dispersion compensators, core mode blockers, in fiber polarizers (Wang Y.P., et al., 2007), couplers (Liu Y., et. al, 2007), and mode converters (Hill K.O., et al., 1990), because of their bandstop filtering characteristics and selective mode coupling between the fundamental mode and the cladding modes.

\section{Sensors of Long Period Fiber Grating}

\subsection{Curvature sensor}

In this section the transmission effects of LPFGs by curves is shown, in Fig. 14 the experimental setup is depicted.

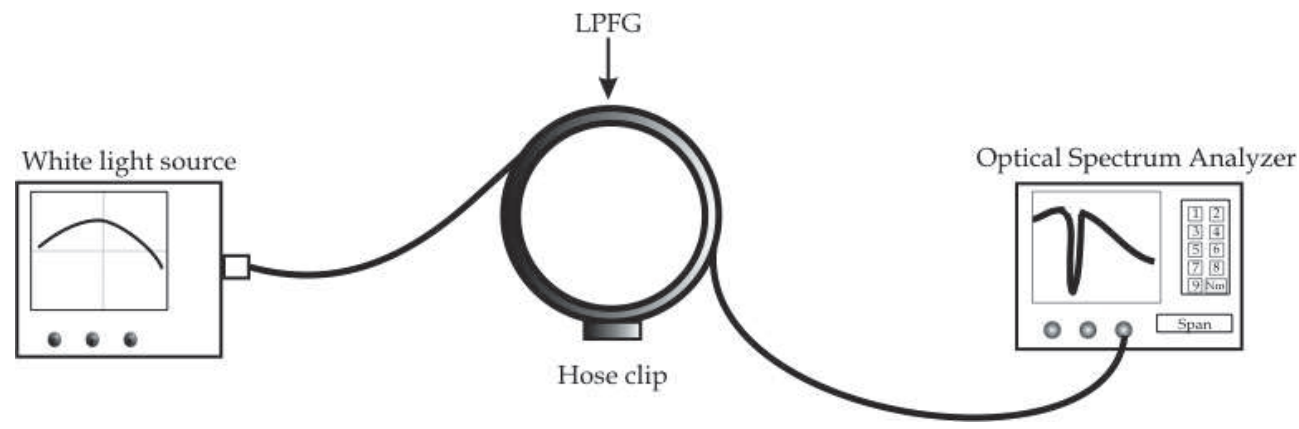

Fig. 14. Experimental setup for sensing diameter of curvature with LPFG by micro-taper modulation

For this experiment, it is necessary to maintain fixed the LPFGs and avoid twisting and LPFGs movements and optical fiber movements, these factors influence the behavior of the attenuation peak of LPFGs. We turned the screw and the hose clip diameter was varied, and then we were measuring the output spectrum of the LPFGs, measurements reduced the diameter of the loop from 13.1 to $12 \mathrm{~cm}$. In Fig. 15, we show the displacement of the attenuation peak to the left as we decrease the diameter of the loop curvature.

In Fig.16, we show the almost linear behavior of the shift in the wavelength of the attenuation peak when the diameter of curvature of the LPFG was decreased. The attenuation peak is shifted by changing the period of the LPFGs. This is due to the change of the diameter of the hose clip. This scheme can serve as a curvature sensor and for tuning a fiber laser. 


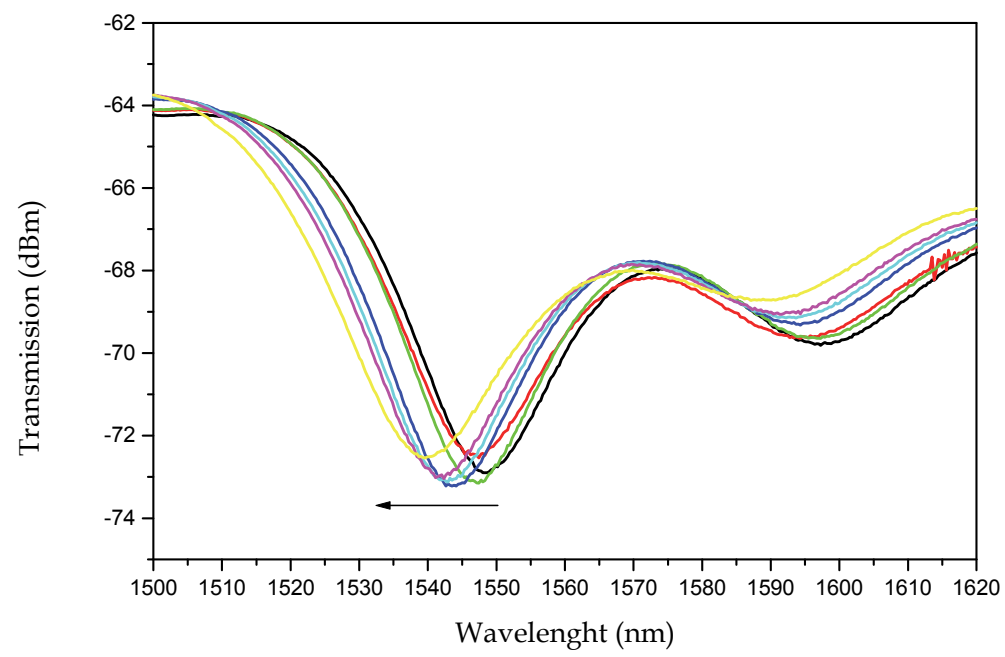

Fig. 15. displacement to left the attenuation peak when decrement the diameter of curvature.

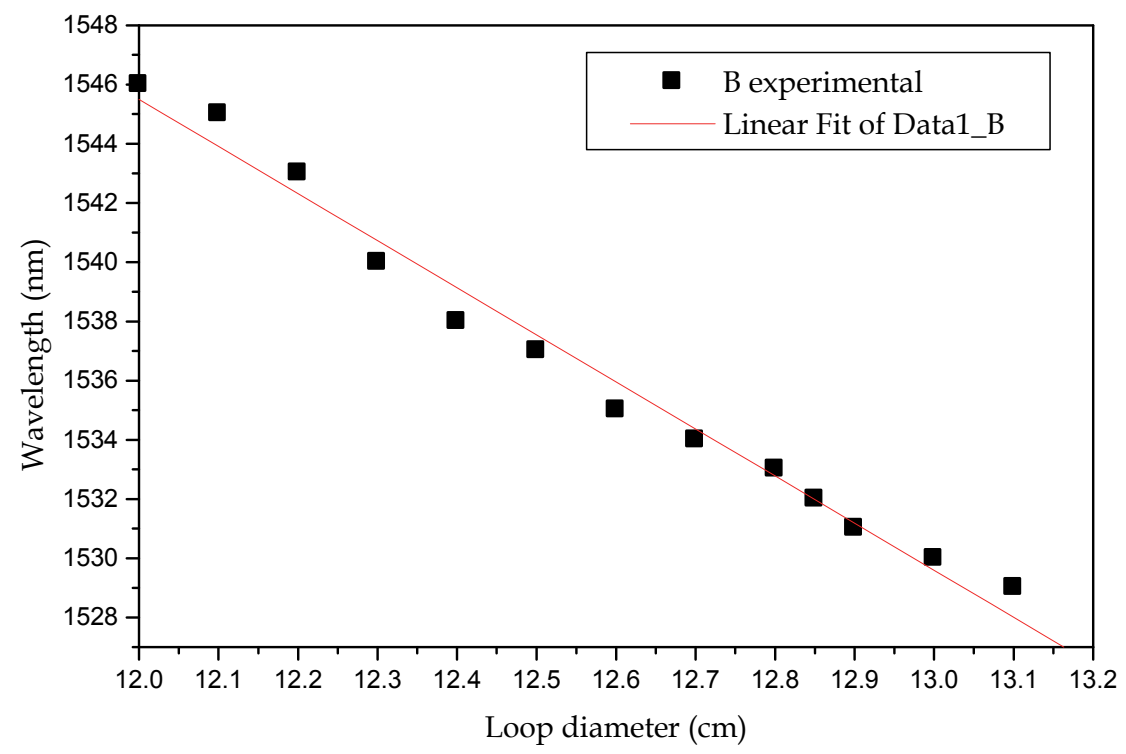

Fig. 16. Linear change of the attenuation peak 


\subsection{Temperature sensor}

Long period gratings are inherently sensitive to changes in temperature of the surrounding environment. This can be observed when a full variation characterizations of the transmission spectra result in shifting of the attenuation band central wavelengths with a possible change in the peak intensity. The chain rule differentiation of the phase matching condition is a common approach to describe the temperature response of the LPFG (MataChávez R.I., et al., 2008b).

$$
\frac{d \lambda}{d T}=\frac{d \lambda}{d\left(\delta\left(n_{\text {eff }}\right)\right)}\left(\frac{d n_{\text {eff }}}{d T}-\frac{d n_{\text {clad }}}{d T}\right)+\Lambda \frac{d \lambda}{d \Lambda} \frac{1}{L} \frac{d L}{d T}
$$

In order to study the temperature effect over the transmission spectrum of the fattened LPG, the experimental setup shown in Fig. 17 was used. The characterization system consists on a fluorescence light source, which is obtained by pumping an Erbium Doped Fiber (EDF) with a laser diode (LD) at $980 \mathrm{~nm}$. A temperature controller in a range of $50-500{ }^{\circ} \mathrm{C}$, and an Optical Spectrum Analyzer (OSA) with a $0.2 \mathrm{~nm}$ spectral resolution (connected with a dashed line in the drawing).

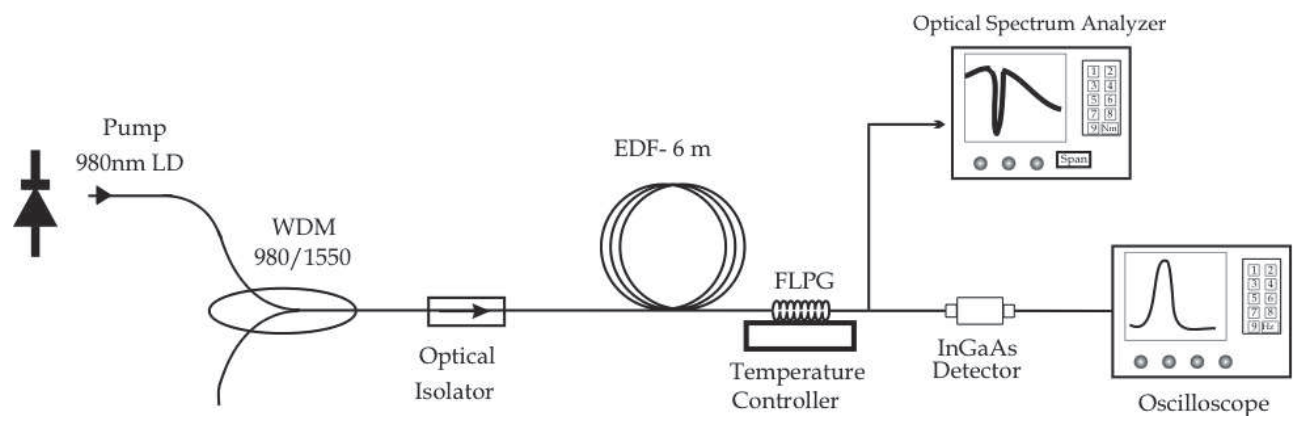

Fig. 17. Experimental setup for LPFG characterizations to study of temperature

When finishing the temperature characterizations, an optical detector and an oscilloscope were placed in the experimental setup, instead of the OSA, to measure the output in volts $/ 100^{\circ} \mathrm{C}$ for the temperature sensor implementation. The detector is a cheaper and smaller device compared to the OSA that is coupled directly to the optical fiber. It is also a better option to read and process light signals with a smaller electronic acquisition data system.

The experimental setup with the OSA in the log scale shows a wavelength shift response which is linear as temperature increases. Resonance wavelength shifting was observed to longer wavelengths. This behavior is observed almost in all the studies presented in literature for temperature characterizations of LPFG in any type of optical fiber (Rego, G., et. al., 2005). The average sensitivity achieved is about $72 \mathrm{pm} /{ }^{\circ} \mathrm{C}$. This is a greater value than the obtained in our previous work with DS-LPFG with a resonance wavelength around $1550 \mathrm{~nm}$ where the fiber was fattened at positions separated by $\sim 25 \mu \mathrm{m}$ (Mata-Chávez R.I., et al., 2008). We think the sensitivity increment is due to the wavelength set inside the loss band and the excited modes within that range as well as the change of the refractive 
effective index with temperature. As the structure changed, modal group dispersion is also modified, changing the thermo optic coefficients of the core and the ring, contributing to the sensitivity increment.

When switching to the linear scale $(\mathrm{mW})$, we observed two interesting situations which can be convenient to implement a temperature sensor around $1550 \mathrm{~nm}$. The optical power of the light source was presented as a peak centered at $1560 \mathrm{~nm}$ and $2.146 \mathrm{~mW}$. The LPFG with a resonant wavelength at $1524 \mathrm{~nm}$, spliced after the EDF, gradually attenuated the optical power as the loss band of the filter shifted to longer wavelengths with temperature increment. On the other hand, if the LPFG with a resonant wavelength at $1550 \mathrm{~nm}$ was used, it instantly attenuated the power spectrum. As the loss band shifted to longer wavelengths, the power spectrum increased gradually with temperature (Fig. 18). This measurement approach gives two options to implement a temperature sensor. Attenuating or increasing the output optical power which depends on the position of the central wavelength of the attenuation band and the laser optical power spectrum. Linearity of the photodiode output voltage with temperature is observed in a range of $25-200^{\circ} \mathrm{C}$. For temperature over 200$500^{\circ} \mathrm{C}$, there is a visible increment of the $\mathrm{dV} / \mathrm{dT}$ of the photodiode output. The highest sensitivity registered in volts is $0.05 \mathrm{mV} /{ }^{\circ} \mathrm{C}$ and the results were repeatable. The insertion losses can be reduced with the improvement of the fabrication method of the DS-LPFG in future works.

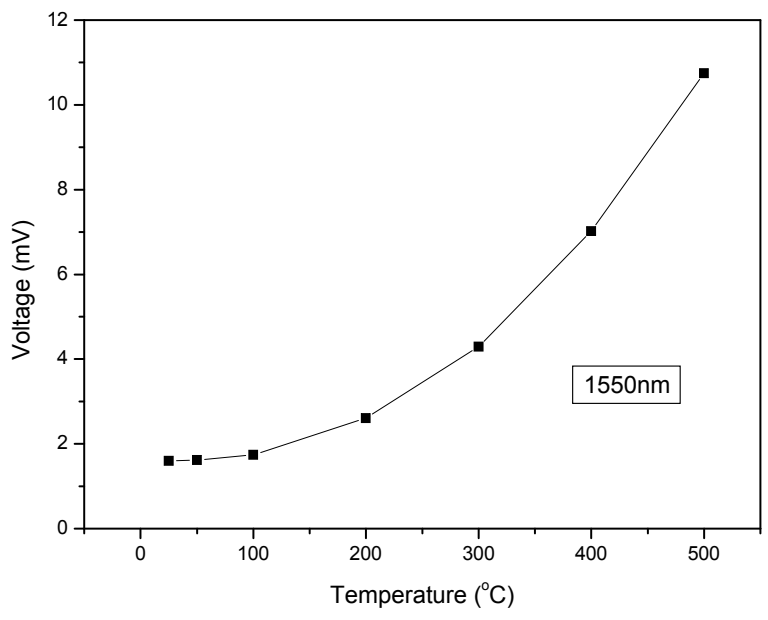

Fig. 18. Power spectrum increment using an LPFG with a central wavelength at $1550 \mathrm{~nm}$.

Then, it shows the characterization of an LPFG with micro-taper modulation, for temperature changes measurements. Once the LPFG was fabricated as described in section (3.6), we used a temperature controller $\left(25^{\circ} \mathrm{C}\right.$ to $\left.500{ }^{\circ} \mathrm{C}\right)$ for heating the grating. Light from a white light source was introduced to the LPFG.The spectrum for each measurement was obtained at the fiber end $\left(50{ }^{\circ} \mathrm{C}, 100{ }^{\circ} \mathrm{C}-500{ }^{\circ} \mathrm{C}\right)$ as shown in the Fig. 19.The attenuation peak is shifted to the right when increasing the temperature from $25^{\circ} \mathrm{C}$ to $500{ }^{\circ} \mathrm{C}$. In Fig. 20, it is 
shown the linear behavior of the attenuation peak against temperature, we obtain those data for each Celsius degree, there was a wavelength variation of $63.15 \mathrm{pm}$.

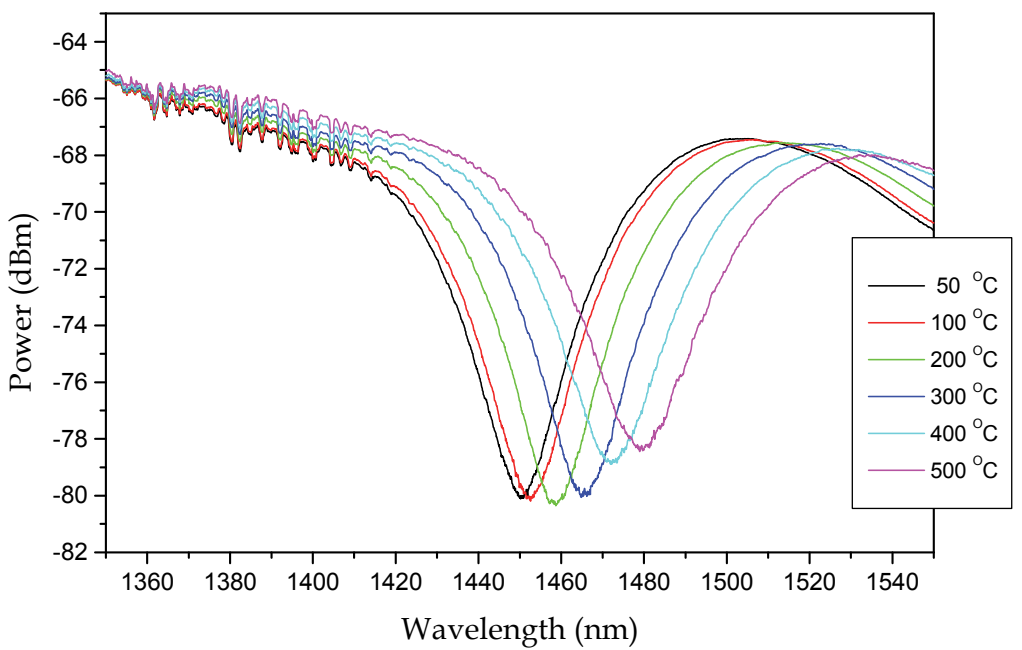

Fig. 19. Displacement of attenuation peak of LPFG to different temperatures.

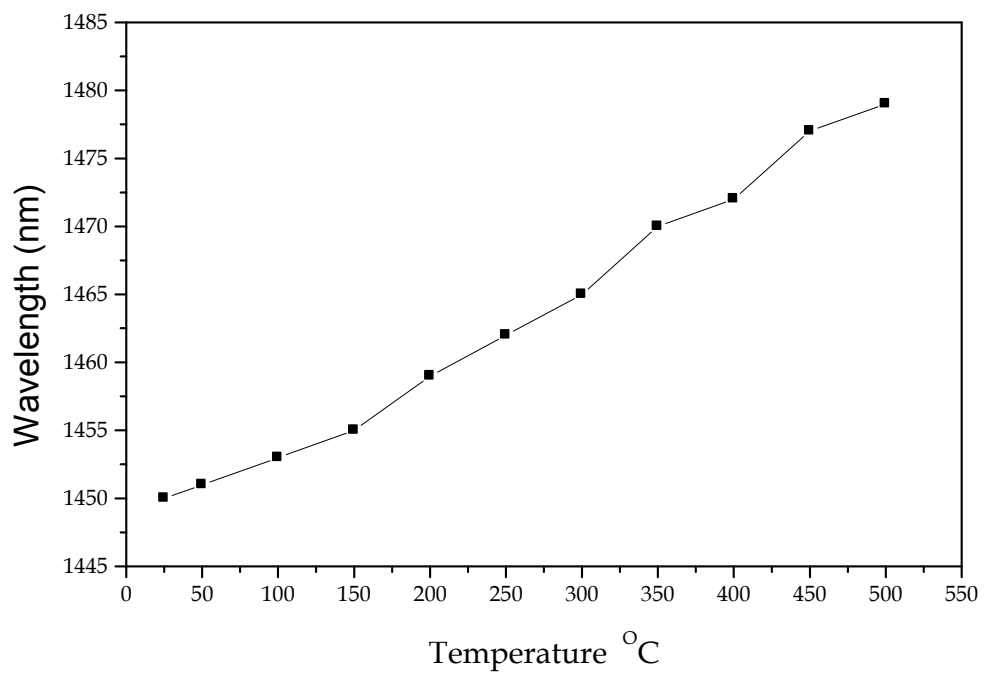

Fig. 20. Linear behavior the attenuation peak against temperature

\section{Introduction to modelling individual Long Period Fiber Grating}

There are several approaches for LPFG modeling to obtain the spectral properties. Some of them are based on previous studies of LPFG by Vengsarkar (1996), Erdogan, (1997), Kashyap, 1999, Othonos \& Kalli, (1999). The coupled-mode theory has been widely applied to model LPFG where an excited mode by the grating can be represented as a linear 
combination of the eigenmodes of the fiber. The phase matching condition is also considered, where a perturbation of the phase of one mode would match the phase of another at the cladding region, see equation 3.1. A system of two coupled mode equations is given by:

$$
\begin{aligned}
& \frac{d A_{c o}(z)}{d z}=i k_{c o-c o} A_{c o}(z)+i \frac{m_{g}}{2} k_{c o-c l} A_{c l}(z) e^{i \delta c} \\
& \frac{d A_{c l}(z)}{d z}=i k_{c l-c o} A_{c o}(z) e^{i 2 \delta c}+i \frac{m_{g}}{2} k_{c l . c l} A_{c l}(z)
\end{aligned}
$$

$A_{c o}$ and $A_{c l}$ are the slowly varying amplitudes of the core and cladding modes, $k_{c o-c o}$, $k_{c o-c l}$ are the coupling coefficients $m_{g}$ the grating modulation depth and $\delta$ is the detuning from the resonant wavelength.

Numerical methods are also applied to the purpose of LPG analysis. It is the case of the Beam Propagation Method (BPM) and transfer-matrix method. These methods are also implemented in commercial software like BPM in RSoft ${ }^{\circledR}$. With this software we have been able to model individual LPFG with fattening. Grating parameters and structure characteristics are introduced in the software to obtain the excited modes in the grating, the effective index, propagation through the grating, and power losses. A prime model considers an ideal complete structure for the LPFG in a dispersion shifted fiber Fig. 21. This fiber structure has a central core and a ring core which in a second part they are modeled by separate to obtain some characteristics as mode excitation. Different wavelengths were used which correspond to wavelength operation to common laboratory lasers. These are $1.55 \mu \mathrm{m}$, $1.31 \mu \mathrm{m}$, and $0.632 \mu \mathrm{m}$ as well as a broad band white light source $(400-1700 \mathrm{~nm})$.

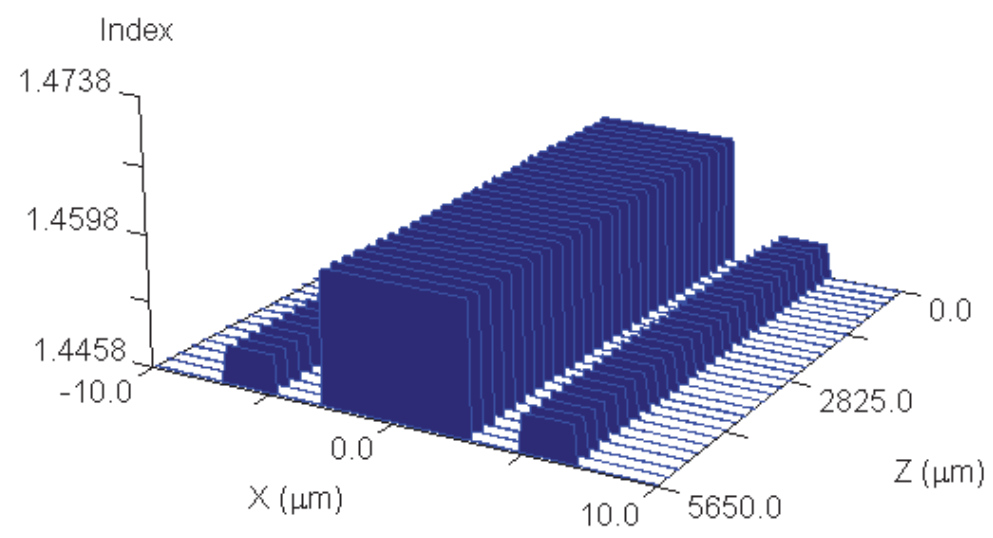

Fig. 21. Idealized step index profile of a dispersion shifted fiber.

The structure radii parameters were: $a=2.9 \mu \mathrm{m}, b=5 \mu \mathrm{m}, c=8 \mu \mathrm{m}$ and the index refraction values : $n 1=1.4598, n 2=1.4498, n 3=1.4498$ and $n 4=1.4458$ (Mata-Chávez R.I., et al., 2008a). To investigate the complete modal characteristics, the fiber structure was divided in two regions as in reference (Mata-Chávez R.I., et. al., 2008b). A central core region and a ring core region, where light is confined and freely propagates along the structure. From this 
analysis it was encounter that only the $\mathrm{LP}_{01}$ and the $\mathrm{LP}_{11}$ modes are excited in the optical fiber. A model of the LPFG with fattening is also considered for the modal analysis and such structure is depicted in Fig. 22.

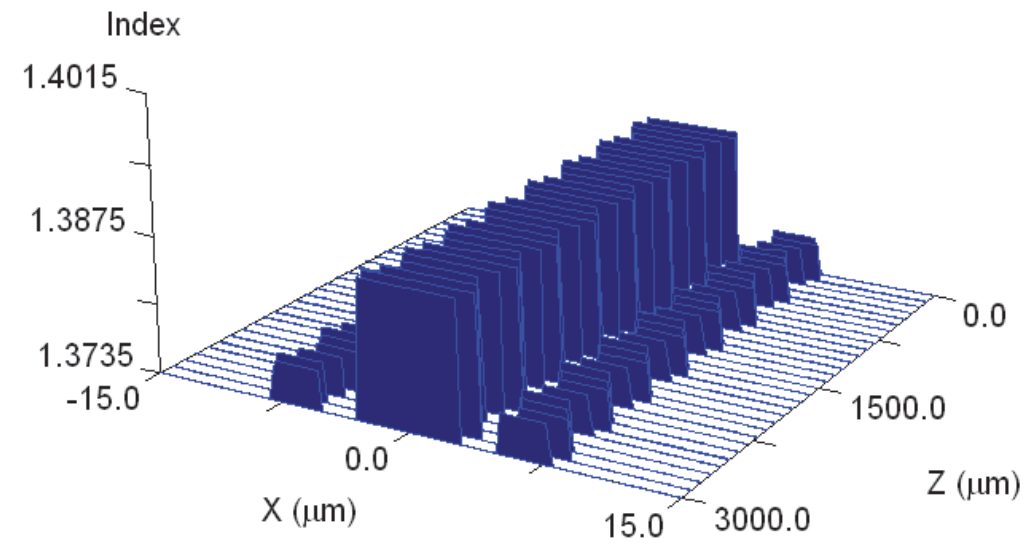

Fig. 22. Idealized step index profile of a dispersion shifted fiber with fattening.
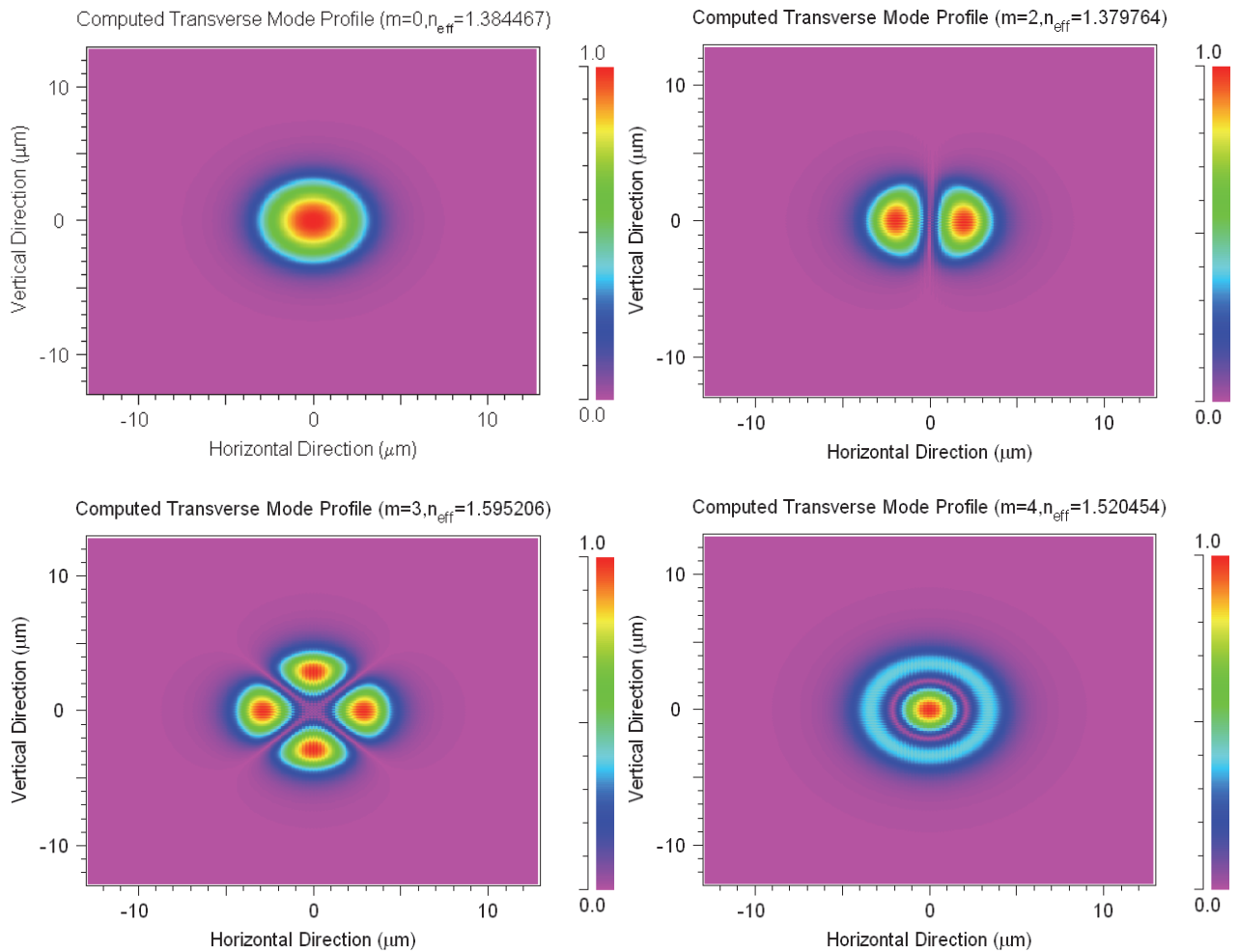

Fig. 23. Excited modes of an LPFG in a dispersion shifted fiber, $L P_{01}, \mathrm{LP}_{11}, \mathrm{LP}_{21}$, and $\mathrm{LP} 03$. 
Propagation of light can also be calculated. Fig. 24 depicts the LPFG with fattening. Several periods were modeled and power losses at the core can be achieved as light propagates. This is because of the energy that couples at the cladding layer due to the phase matching condition. The effective index of refraction can also be calculated as well as the LPFG transmission. This helps to compare the experimental results with the theoretical ones.
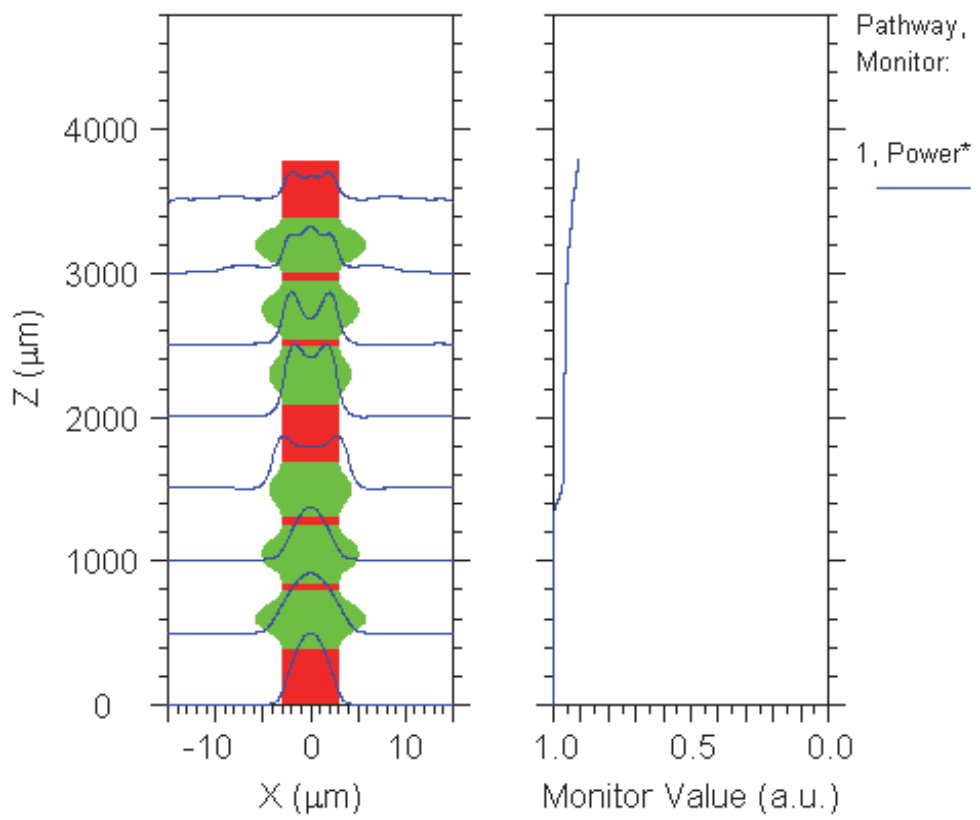

Fig. 24. Power loss at the core in a LPFG with fattening.

\section{Conclusion}

The main advantage of method of arc dischargers to fabricate long period fiber grating results from the fact that it can be implemented in any commercial fusion splicer, therefore, there are many potentialities of the electric arc technique to produce optical devices in an easy and fast way as sensors, filters and equalizers in any optical fiber. We presented the sensing of curvature and temperature, by means of long period fiber grating that we have fabricated by the method of micro-taper and fattening, and both present good sensitivity as much as $72 \mathrm{pm} /{ }^{\circ} \mathrm{C}$. This type of filter has potential applications in biochemical sensing, environment monitoring, stress, curvature and its principal advantages are that is compact, light and of low cost. One disadvantage of the electric arc method is the unrepeatability of the physical and optical characteristics of the fabricated filters due to the uncontrolled, in most cases, application of the electric arc discharges.

\section{Acknowledgment}

This work was supported by "División de Ingenierías del Campus Irapuato-Salamanca, Universidad de Guanajuato" and DAIP 2010 E20391. 


\section{References}

An H., Ashton B., and Fleming S., (2004), Long-period-grating-assisted optical add-drop filter based on mismatched twin-core photosensitive-cladding fiber, Opt. Lett. Vol. 29, pp. 343-345.

Bhatia V. and Vengsarkar A.M., (1996) Optical fiber long-period grating sensors, Opt. Lett. Vol 21, pp. 692.

Davis, D. D., Gaylord, T. K., Glytsis, E. N. and Mettler, S. C. (1998) CO2-laser-induced longperiod-fibre gratings: Spectral characteristics, cladding modes, and polarisation independence, Electron. Lett., vol. 34, pp. 1416-1417.

Davis, D. D., Gaylord, T. K., Glytsis, E. N. and Mettler, S. C. (1999) Very-high-temperature stable CO2-laser-induced long-period fibre gratings, Electron. Lett., vol. 35, pp. 740742.

Dobb H., Kalli K., and Webb D. J., (2004) Electron. Lett. Vol. 40, pp. 657.

Eggleton B. J., Slusher R. E., Judkins J. B., Stark J. B., and Vengsarkar A. M., (1997) All-optical switching in long-period fiber gratings, Opt. Lett. Vol. 22, 883-885.

Erdogan T. (1997) Cladding-mode resonances in short and long-period fiber grating filters, Journal of the Optical Society of America A, Vol 14, pp 1760-1773.

Glogle D. 1971 Weakly guiding fiber, Appl. Opt. Vol. 10, pp 2252-8.

Grobnic D., Mihailov S. J., Smelser C. W., Becker M., and Rothhardt M. W., (2006) Femtosecond laser fabrication of Bragg gratings in borosilicate ion-exchange waveguides, IEEE Photonics Technol. Lett. Vol. 18, pp. 1403-1405

Han Y. -G., Kim S., and Lee S., (2004) Flexibly tunable multichannel filter and bandpass filter based on long-period fiber gratings, Opt. Express Vol. 12, pp. 1902-1907.

Hernández-García J.C., Estudillo-Ayala J.M., Rojas-Laguna R., Mata Chávez R.I., MartínezRíos A., Gutiérrez J.G., Trejo-Durán M., Vargas-Rodríguez E., Andrade-Lucio J.A. and Alvarado-Méndez E.(2010), Instrumentation and design of a high voltage source to produce optical fiber gratings by the electric arc technique, Revista Mexicana de Física Vol 56 pp. 255-2612.

Hill K.O., Malo B., Vineberg K.A., Bilodeau F., Jonson D.C., Skinner I.(1990) Efficient mode conversion in telecommunication fiber using externally written gratings, Electron. Lett. Vol. 26, 1270-1272.

Hill, K.O., B. Malo, F. Bilodeau, D.C. Johnson, and J. Albert. (1993). Bragg gratings fabricated in monomode photosensitive optical fiber by UV exposure through a phase mask, Applied Physics Letters. Vol. 62, pp. 1035-1037.

Hill, K.O., and G. Meltz. (1997). Fiber Bragg Grating Technology Fundamentals and Overview. Journal of Lightwave Technology. Vol. 15, No. 8, pp. 1263-1276.

Hill, K.O. (2000). Photosensitivity in Optical Fiber Waveguides: From Discovery to Commercialization. IEEE Journal on Selected Topics in Quantum Electronics. Vol. 6, No. 6, pp. 1186-1189.

Humbert G., Malki A., Fevrier S., Roy P., and Pagnoux D., (2003) Electron. Lett. Vol. 39, pp. 349

Hwang, I. K., Yun, S. H. and Kim, B. Y. (1999) Long-period fiber gratings based on periodic microbends, Optics Letters, Vol.24 pp 1263-1265.

Kakarantzas G., Dimmick T. E., Birks T. A., Le Roux R., and Russell P. S. J., (2001), Opt. Lett. Vol. 26, pp. 1137.

Kashyap R., (1999) fiber Bragg grating, Academic Press. 
Kersey, A. D., Davis M A, Patrick Heather J, LeBlanc M, Koo K P, Askins C G, Putnam M A and Friebele E J (1997) Fiber grating sensors J. Lightwave Technol. Vol. 15 pp. 1442 63.

Mata-Chávez R.I. , Martinez-Rios A., Torres-Gomez, I., Alvarez-Chavez, J.A., SelvasAguilar, R., Estudillo-Ayala, J. M (2008) Wavelength band-rejection filters based on optical fiber fattening by fusion splicing, Optics E Laser Technology, Vol. 40 pp. 671675.

Mata-Chávez R.I. Martínez- Rios. A. Torres-Gémez I., Selvas-Aguilar R., Estudillo-Ayala J.M. (2008) Mach-Zehnder All- Fiber interferometer Using Two in-Series Fattened fiber grating, Optical Review, Vol. 15 pp 1-6.

Meltz, G., W. W. Morey, and W. H. Glenn. (1989). Formation of Bragg Gratings in Optical Fibers by a Transverse Holographic Method. Optics Letters, Vol. 14, pp. 823-825.

Mihailov S. J., Grobnic D., Huimin D., Smelser C. W., and Jes B., (2006) Femtosecond IR laser fabrication of Bragg gratings in photonic crystal fibers and tapers, IEEE Photonics Technol. Lett. Vol. 18, pp.1837-1839.

Myoungwon K., Dongwook L., Bum I. H. and Haeyang C. (2002). Performance Characteristics of Long-Period Fiber-Gratings Made from Periodic Tapers Induced by Electric-arc Discharge, Journal of the Korean Physical Society, Vol. 40 pp. 369-373.

Lin C. Y., Chern G. W., and Wang L. A., (2001), Periodical corrugated structure for forming sampled fibre Bragg grating and long-period fiber grating with tunable coupling strength, J. Lightwave Technol., Vol. 19 pp.1212-1220.

Liu Y., Chiang K.S., Rao Y.J. , Ran Z.L., and Zhu T. (2007) Light coupling between two parallel $\mathrm{CO}_{2}$-laser written long-period fiber gratings, Optics Express, Vol. 15, pp. $17645-17651$.

Othonos, A. (1997) Fiber Bragg Gratings. Reviews of Science Instruments, Vol. 68, No. 12, pp. 4309-4341.

Rego G., (2006) Chapter 3: Mechanisms of formation of arc-induced long-period fibre gratings" in Arc-induced long-period fibre gratings: fabrication and their applications in optical communications and sensing, University of Porto.

Rego G, Marques P.V.S., Santos J.L., Salgado H.M. (2005) Arc-induced long period gratings. Fiber Integrated Opt, Vol. 24 pp. 245-59

Rego G. M., Santos J. L., and Salgado H. M., (2006) Opt. Commun. Vol. 262, pp.152

Rego G. (2010) Fiber optic devices produced by arc discharges, J.Opt. Vol. 12 pp. 113002.

Riant I. (2002) UV-photoinduce fibre grating for gain equalisation, Optical Fiber Technology, Vol. 8, pp. 171-194.

StephenW.J. and Ralph P. T. (2003) Optical fibre long-period grating sensors: characteristics and application Meas. Sci. Technol. Vol 14 pp R49-R61.

Su L., Chiang K. S., and Lu C., (2005), Microbend-induced mode coupling in a graded-index multimode fiber Appl. Opt. Vol. 44, pp. 7394-7402.

Udd, E. (1991) Fiber Optic Sensors: An Introduction for Scientists and Engineers. New York: ed., John Wiley and Sons.

Vengsarkar A. M., Lemaire P. J., Judkins J. B., Bhatia V., Erdogan T., and Sipe J. E., (1996) Long-period fiber gratings as band-rejection filters, J. Lightwave Technol., vol. 14, pp. 58-65.

Vengsarkar A. M., Pedrazzini, J. R., Judkins, J. B., Lemaire, P. J. and Bergamo, N. S. (1996), Optics Letters., Vol 21, pp 336. 
Von Bibra M. L., Roberts A., and Canning J., (2001) Fabrication of long-period fiber gratings by use of focused ion-beam irradiation Opt. Lett. Vol. 26, pp.765

Wang Y.P., Xiao L.M., Wang D. N., and Jin W., (2007) In-fiber polarizer based on a longperiod fiber grating written on photonic crystal fiber Opt. Lett., vol. 32, pp. 10351037

Yablon A. D. (2005) Optical Fiber Fusion Splicing. Springer. Chap 8. 226 


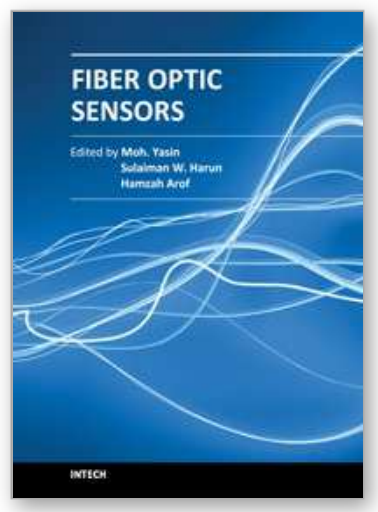

\author{
Fiber Optic Sensors \\ Edited by Dr Moh. Yasin
}

ISBN 978-953-307-922-6

Hard cover, 518 pages

Publisher InTech

Published online 22, February, 2012

Published in print edition February, 2012

This book presents a comprehensive account of recent advances and researches in fiber optic sensor technology. It consists of 21 chapters encompassing the recent progress in the subject, basic principles of various sensor types, their applications in structural health monitoring and the measurement of various physical, chemical and biological parameters. It also highlights the development of fiber optic sensors, their applications by providing various new methods for sensing and systems, and describing recent developments in fiber Bragg grating, tapered optical fiber, polymer optical fiber, long period fiber grating, reflectometry and interefometry based sensors. Edited by three scientists with a wide knowledge of the field and the community, the book brings together leading academics and practitioners in a comprehensive and incisive treatment of the subject. This is an essential reference for researchers working and teaching in optical fiber sensor technology, and for industrial users who need to be aware of current developments and new areas in optical fiber sensor devices.

\title{
How to reference
}

In order to correctly reference this scholarly work, feel free to copy and paste the following:

Julián M. Estudillo-Ayala, Ruth I. Mata-Chávez, Juan C. Hernández-García and Roberto Rojas-Laguna (2012). Long Period Fiber Grating Produced by Arc Discharges, Fiber Optic Sensors, Dr Moh. Yasin (Ed.), ISBN: 978953-307-922-6, InTech, Available from: http://www.intechopen.com/books/fiber-optic-sensors/long-periodfiber-grating-produced-by-arc-discharges

\section{INTECH}

open science | open minds

\section{InTech Europe}

University Campus STeP Ri

Slavka Krautzeka 83/A

51000 Rijeka, Croatia

Phone: +385 (51) 770447

Fax: +385 (51) 686166

www.intechopen.com

\section{InTech China}

Unit 405, Office Block, Hotel Equatorial Shanghai

No.65, Yan An Road (West), Shanghai, 200040, China

中国上海市延安西路65号上海国际贵都大饭店办公楼405单元

Phone: +86-21-62489820

Fax: $+86-21-62489821$ 
(C) 2012 The Author(s). Licensee IntechOpen. This is an open access article distributed under the terms of the Creative Commons Attribution 3.0 License, which permits unrestricted use, distribution, and reproduction in any medium, provided the original work is properly cited. 